\title{
Logística Portuária e Integração do Território Fluminense
}

Linovaldo Miranda Lemos ${ }^{1}$

Rejane Cristina de Araujo Rodrigues ${ }^{2}$

\section{Resumo}

Neste artigo propõe-se um viés interpretativo que procura ultrapassar a dicotomia capital-interior que tanto caracterizou o debate político e acadêmico sobre o Estado do Rio de Janeiro. Assim, defende-se a ideia de que vem ocorrendo uma transformação na dinâmica territorial do estado, o que vem progressivamente amalgamando as suas diversas regiões em função do crescimento e da dinamização de certas atividades econômicas bem como do papel desempenhado pelas redes logísticas articuladas aos portos. Para isso, discute-se o papel atribuído ao setor portuário, a partir da análise de projetos elaborados pela FIRJAN, como um elemento que consolidaria o Estado do Rio de Janeiro como importante nó de uma rede logística regional e nacional. Estas transformações tornariam necessários novos aportes tanto do ponto de vista teórico quanto do da implementação das políticas públicas.

Palavras-chave: Rio de Janeiro; logística; portos; dinâmicas territoriais fluminenses

\begin{abstract}
This article proposes an interpretive bias that seeks to overcome the dichotomy capital countryside that has characterized so markedly the political and academic debate on the State of Rio de Janeiro. Thus, argues that there is an ongoing transformation in the spatial dynamics of the state, which has progressively amalgamated its various regions due to the growth and dynamism of economic activities and the role played by logistics networks in conjunction with the ports. For this, discusses the role assigned to the port sector from the analysis of FIRJAN's projects that would consolidate the Rio de Janeiro as an important node in a regional and national logistics network. These changes would make it necessary new contributions both from the theoretical point of view as the implementation of public policy.
\end{abstract}

Keywords: Rio de Janeiro; logistics; ports; territorial fluminense dynamics

\footnotetext{
1 Linovaldo Miranda Lemos é doutor em Geografia (UFRJ), professor do Instituto Federal Fluminense (IFF). lino.m.lemos@gmail.com 2 Linovaldo Miranda Lemos é doutor em Geografia (UFRJ), professor do Instituto Federal Fluminense (IFF). lino.m.lemos@gmail.com Rejane Cristina de Araujo Rodrigues é doutora em Geografia (UFRJ), professora da Pontifícia Universidade Católica do Rio de Janeiro (PUC-Rio), professora do Instituto de Aplicação da Universidade Estadual do Rio de Janeiro (CAp-UERJ). rcarodrigues@gmail.com
} 


\section{Introdução}

O Estado do Rio de Janeiro possui características que o singularizam ante aos demais entes da Federação. Em que pese ser esta a $4^{\mathrm{a}}$ menor unidade territorial do país, perfazendo 0,5\% do território nacional, abriga o segundo maior contingente populacional bem como a segunda maior economia do país medida por do seu Produto Interno Bruto (PIB). Do ponto de vista de sua configuração territorial, o estado é fruto de um processo histórico no qual diferentes relações se estabeleceram entre a sua atual capital, a cidade do Rio de Janeiro, e as demais regiões fluminenses. Pode-se considerar que este processo histórico, no que se refere à construção do seu território, incorporou forças de aproximação e distanciamento entre a cidade do Rio de Janeiro e as demais regiões que compõem o estado.

De sua centralidade política ao longo da história, a cidade do Rio de Janeiro assistiu à fusão levada a cabo pelo governo militar. Tal processo autoritário trouxe consigo efeitos deletérios, tanto do ponto de vista político quanto do econômico. Duas realidades distintas foram justapostas, deixando consigo como herança a "ausência do imaginário de um pertencer coletivo das populações, em função da inexistência de coesão e de laços de solidariedade territorial” (Davidovich, 2001).

Embora se admita que estas realidades distintas sejam variáveis intrínsecas ao debate, pretende-se focar, neste artigo, nas dinâmicas territoriais atuais que dão unidade ao estado, mormente no seu papel logístico, dando-se ênfase especial ao papel desempenhado pelos portos nesse contexto.

Assim, as ideias aqui defendidas procuram corroborar a tese de Limonad (2004) de que ocorre "uma mudança substantiva no papel das diversas áreas do interior fluminense", bem como de que há uma "nova ordem territorial” (Binsztok, 1999), para além da capital e da região metropolitana, acrescentando ao debate o importante papel da logística portuária como um amálgama desse processo. Ao assim procedermos, pretendemos lançar luz sobre a complexidade e diversidade regional do Estado do Rio de Janeiro sem, contudo, desconsiderar a primazia, o peso, da sua região metropolitana.

Portanto, a atualização do debate aponta para a necessidade de focar nas dinâmicas internas do estado, tomando-as como uma realidade única, interligada e interdependente de um estado que passa por um processo de crescimento econômico e por uma dinamização das atividades não só na capital como também no seu interior. Ao ser encarado dessa forma, o desafio passa a ser o de compreender como o papel de centro logístico atribuído ao estado vem concatenando o território fluminense e tornando necessário novos aportes que se traduzam em interpretações que avancem para além daquela tradicional dicotomia capital-interior.

Além da Introdução, o artigo está estruturado de forma a, na primeira parte, atualizar o debate acadêmico sobre a relação capital-interior apontando como as discussões se direcionaram para o entendimento de que a diversificação das atividades produtivas regionais se configurou a partir de "eixos" de desenvolvimento capitaneados pelas rodovias. Na segunda parte analisam-se os projetos, com atenção particular àqueles organizados pela FIRJAN com forte influência na definição de políticas territoriais para o Estado do Rio de Janeiro, que apontam a importância do Estado do Rio de Janeiro como um nó central da logística de transportes na Região Sudeste, para o MERCOSUL e para o Brasil, ao passo que, na terceira parte, analisa-se a rede logística do Estado do Rio de Janeiro, incluindo as mudanças mais recentes em termos da instalação de novos terminais, de portos secos e de terminais multimodais e a configuração territorial organizada a partir da implementação de uma racio- 
nalidade logística que tem nos portos seus nós centrais. Como conclusão procede-se à articulação entre a questão da relação capital-interior e o novo papel desempenhado pela logística portuária e de transportes no estado.

\section{1 - A relação capital-interior no Estado do Rio de Janeiro: entre dicotomias e novas confi- gurações territoriais}

A trajetória histórica da configuração territorial do Estado do Rio de Janeiro, como apontado anteriormente, foi marcada pelo papel de centro político (e, até certo ponto, econômico) da cidade do Rio de Janeiro na sua relação com o país e com a sua hinterlândia imediata. Uma situação sui generis foi criada na qual após um longo período desempenhando o papel de centro político, a cidade perde seu status de capital nacional para, na década de 1970, se tornar um novo ente federado a partir da fusão dos dois territórios.

Como resultado, autores sublinham a carência de uma coesão interna ao estado (Davidovich, 2001), bem como uma separação e autonomia entre a capital e o interior. Nas palavras de Maria do Carmo Galvão ocorreu

\footnotetext{
A justaposição de dois segmentos espaciais politicamente "descolados" um do outro, embora fisicamente embutidos um no outro [...]. Voltados para atividades econômicas específicas e para funções sociais e administrativas definidas e delimitadas [...] a cidade e o Estado criaram ao longo da história duas vidas, se não autônomas, pelo menos paralelas e relativamente independentes. (Galvão, 2009:89)
}

Mais do que "descolados” um do outro, segundo a mesma autora, a condição de capital do estado da Guanabara “cerceou sua atuação regional e propiciou a eclosão de forças de inércia que explicam a estagnação de largas porções do território, especialmente em seu setor rural” (op. cit, p. 90). Portanto, a fusão, nessa linha, teria representado "a simbiose da cidade rica com um estado falido" (Jornal do Brasil, 13/11/94 apud Limonad, 2004), o que provocou o "esvaziamento" econômico da cidade do Rio, em função, dentre outros fatores, da relação parasitária do interior em relação à capital (Limonad, 2004:79).

Não sem motivos, Cruz (2013) considera que os estudos sobre o tema são "cariocacentrados", aparecendo o interior como um "apêndice" do estado. Acrescentaríamos que outro traço marcante dessas interpretações é a referência ao esvaziamento econômico da capital, seja em função da transferência da capital para Brasília nos anos de 1960, seja pela imposição de uma nova engenharia territorial ${ }^{3}$ com a fusão, em 1975, e a necessidade da cidade do Rio de Janeiro de absorver o chamado "interior", num novo estado (Lessa; 2000; Osório, 2005).

Com o avanço das atividades petrolíferas, a expansão dos investimentos públicos e privados e a emergência da cidade do Rio de Janeiro como centro de grandes eventos, o foco desloca-se dessa condição de "crise" para a análise da "hora da virada" do Rio de Janeiro (Urani, 2008; Urani e Giambiagi, 2010) ou da análise dos desafios e das oportunidades defraudadas a partir dessas transformações, seja com o foco no crescimento econômico e nas mudanças estruturais da economia, seja nos desafios às instituições políticas no que se refere à gestão fiscal e orçamentária ou nos aspectos sociais como a violência urbana, a educação ou o acesso aos serviços (Pinheiro e Veloso, 2012). Nessa mesma direção, um conjunto de pesquisas que tem o Estado do Rio de Janeiro como objeto de análise, mormente na sua relação com o 
chamado "interior", acabaram por superar ou matizar aquelas interpretações simplificadoras da realidade socioespacial do estado. Nesse sentido, pôde-se demonstrar, nesses trabalhos, a crescente importância das regiões interioranas como foco analítico sobre as condições de crescimento do estado, dando-se especial importância a diferentes experiências e realidades dos municípios (Fauré e Hasenclever, 2003 e 2005; Fauré, Hasenclever e Neto, 2008).

Nesta relação capital-interior há o fato inegável da própria preponderância que a cidade e a Região Metropolitana do Rio de Janeiro desempenham no contexto estadual, superando em muito as demais regiões fluminenses. No Quadro 1 está indicada a participação do PIB estadual das regiões de governo do Estado do Rio de Janeiro, no período de 1999 a 2011, em termos percentuais. Esse mesmo crescimento não se deu uniformemente por todas as regiões do estado tendo em vista que, por exemplo, enquanto o noroeste fluminense tenha apresentado um baixo crescimento perdendo pontos inclusive na sua participação relativa no PIB estadual no período (de 1,27\%, em 1999, para 1,02, em 2011), no norte fluminense, por seu turno, houve incremento na sua participação relativa no PIB estadual, passando de 5,20\%, em 1999, para 15,05, em 2011. Por outro lado, fica evidente que há significativa concentração do PIB estadual na região metropolitana, muito embora, em termos percentuais, esta região tenha perdido participação relativa no período analisado (77,11\%, em 1999, caindo para 62,62, em 2011).

Quadro 01

Produto Interno Bruto das Regiões do Estado do Rio de Janeiro - 1999, 2005 e 2011 (\%)

\begin{tabular}{|c|c|c|c|}
\hline & 1999 & 2005 & 2011 \\
\hline Metropolitana & 77,11 & 67,87 & 62,62 \\
\hline Noroeste Fluminense & 1,27 & 1,29 & 1,02 \\
\hline Norte Fluminense & 5,20 & 11,71 & 15,05 \\
\hline Serrana & 4,13 & 3,64 & 4,15 \\
\hline Baixadas Litorâneas & 3,19 & 6,75 & 7,10 \\
\hline Médio Paraíba & 6,78 & 6,57 & 6,05 \\
\hline Centro-Sul Fluminense & 1,24 & 1,01 & 1,05 \\
\hline Costa Verde & 1,09 & 1,17 & 2,97 \\
\hline
\end{tabular}

Contudo, é necessário reafirmar que, embora se possa apontar uma redistribuição espacial das atividades produtivas no Estado do Rio, este continua a ser um "espaço metropolizado" (Alentejano, 2005) ou um "estado metropolitano" (Ribeiro, 2013), dado o papel de comando da região metropolitana, o que significa dizer, sua preeminência econômica, social e política traduzida, entre outros fatores, pela concentração de $74 \%$ da população total do estado. Essa constatação, no entanto, não significa reforçar a interpretação do interior parasitário - ou levado a reboque pela região metropolitana - tendo em vista as tendências e transformações processadas ao longo das últimas décadas que apontam para uma complexificação das dinâmicas territoriais do estado.

Um viés interpretativo dessas mudanças pode ser baseado no papel desempenhado pelas rodovias como componentes da distribuição da população e das atividades produtivas no estado, por sua capacidade de dinamização dos fluxos e pela atração de população e atividades econômicas. Nesse sentido, baseados em Limonad (2004) e Medeiros Junior (2013), podemos associar os grandes eixos viários que cortam o estado ao dinamismo das atividades industriais das diversas regiões: a BR-116, a Rodovia Presidente Dutra e o polo metal mecâ- 
nico e automobilístico cortando a região do Médio Vale do Paraíba entre a cidade do Rio de Janeiro e São Paulo; a BR-040 que representa importante corredor para Duque de Caxias e a atividade Petroquímica (REDUC) e a Região Serrana do Rio de Janeiro, importante região do turismo, agricultura de hortifrutigranjeiros, têxtil além de polo de tecnologia; a BR-101, tanto no seu sentido norte interligando a capital aos polos da indústria petrolífera, especialmente Macaé e Campos, bem como no seu sentido sul, da capital em direção ao Porto de Itaguaí, no Município de Sepetiba, onde se destacam a indústria naval e o turismo da chamada Costa Verde.

Interligando a BR-101/Norte à BR-101/Sul encontra-se em fase de construção o Arco Metropolitano do Rio de Janeiro, retirando-se o trânsito pesado das vias urbanas da região metropolitana principalmente das já sobrecarregadas BR-101, no trecho entre Manilha e a Ponte Rio-Niterói e a Avenida Brasil. Além da interligação da BR-101 Norte e Sul e dessas com a BR-040, o Arco Metropolitano possibilitará a construção de terminais logísticos e interligação dos portos do Rio de Janeiro e Itaguaí abrangendo uma extensa área no entorno da Baía de Guanabara (FIRJAN, 2007).

Além dessas rodovias federais, cabe acrescentar o importante papel desempenhado pela RJ-106, Rodovia Amaral Peixoto, como elemento fundamental no entendimento dessas novas dinâmicas, principalmente do ponto de vista do espraiamento da população e da criação de uma rede de municípios interligados e, em maior ou menor grau, interconectados na porção costeira da Região das Baixadas Litorâneas até Macaé, no Norte fluminense.

Apesar de concordarmos com a importância dos grandes eixos viários para as mudanças indicadas na relação capital-interior, queremos, neste artigo, chamar atenção para o papel da logística portuariana na definição da dinâmica territorial fluminense, o que faremos a seguir.

\section{1 - O Rio de Janeiro como um estado de logística}

Para além das análises que dão destaque à capital do Estado do Rio de Janeiro e a sua região metropolitana, chamaremos a atenção para os projetos que consideram o estado numa perspectiva de integração capital-interior, ou melhor, como uma unidade logística. ${ }^{4} \mathrm{~A}$ análise desses projetos tem como objetivo contribuir para avançar na discussão das dinâmicas territoriais atuais que dão unidade ao estado, argumento que norteia o estudo ora apresentado.

Foram selecionados trabalhos desenvolvidos pela FIRJAN (Federação das Indústrias do Estado do Rio de Janeiro), com ênfase naqueles que apontam para a importância do estado como centro logístico. ${ }^{5}$ A opção pela análise dos projetos elaborados pela FIRJAN está relacionada à importância histórica de sua atuação nos processos decisórios que afetam o Estado do Rio de Janeiro. Batista (2006:255) ressalta a participação da Federação na conformação de um novo arranjo institucional local "seja com base nas relações imateriais, na disseminação de conhecimento e de capacidades inovativas, especialmente organizacionais, seja na definição formal e tácita de normas de ação e conduta nas relações entre os agentes”. Beloch e Fagundes (1997:186) reforçam esta ideia, demonstrando que a FIRJAN ultrapassou sua atuação como representação industrial para atuar como uma instituição que aponta as

4 A logística refere-se a uma combinação entre infraestrutura, normas/regulações e operações destinada a dar maior fluidez, com menores custos, à circulação de produtos materiais e imateriais.

5 Infraestrutura de Longo Alcance para o Desenvolvimento Sustentado, Rio de Janeiro, um Estado de Logística; Mapa do Desenvolvimento do Estado do Rio de Janeiro, 2006-2014; Decisão Rio: investimentos 2013-2014. 
vantagens comparativas do estado, articula ações e influencia nas definições de políticas públicas.

A crise econômica que castigou o Estado do Rio de Janeiro nas décadas de 1980 e 1990 levou a FIRJAN a empenhar maiores esforços no sentido de pensar e propor projetos mais amplos destinados à recuperação da economia fluminense. Contando com a participação de empresas, organismos governamentais e instituições em diversos segmentos, a FIRJAN organizou alguns projetos de desenvolvimento para o Estado do Rio de Janeiro (Polo de Fruticultura Irrigada, Rio-Capital Petróleo e outros). No âmbito da logística e da infraestrutura do estado, desenvolveu pesquisas nas quais é ressaltada a posição estratégica do Estado do Rio de Janeiro. ${ }^{6}$

O estudo "Infraestrutura de Longo Alcance para o Desenvolvimento Sustentado", (Batista, 1997), encomendado e publicado pela FIRJAN, condicionava o desenvolvimento econômico do estado a três vetores de infraestrutura (comunicações, energia e logística de transportes). A ampliação dos investimentos no setor portuário era apresentada como "uma oportunidade" para a transformação do estado num "hub $b^{7}$ econômico". A distância física das principais áreas de produção industrial e agropecuária no Brasil e dos principais centros produtores e receptores de cargas no mundo seria, de acordo com esse estudo, superada pelos ganhos logísticos. Nesse estudo chama a atenção, em especial, o papel do interior na estratégia de desenvolvimento do Estado do Rio de Janeiro (Figura 1). Ao Porto de Itaguaí (instalado na região metropolitana) caberia a função de nó de ligação da economia nacional com o comércio internacional, devendo ser estimuladas atividades econômicas que incorporassem o interior do estado como espaço da retrologística, aparecendo a construção do Porto do Açu e a ampliação do Porto de Macaé como importantes ações.

Figura 1

Pilares de sustentação do projeto de desenvolvimento do Estado do Rio de Janeiro

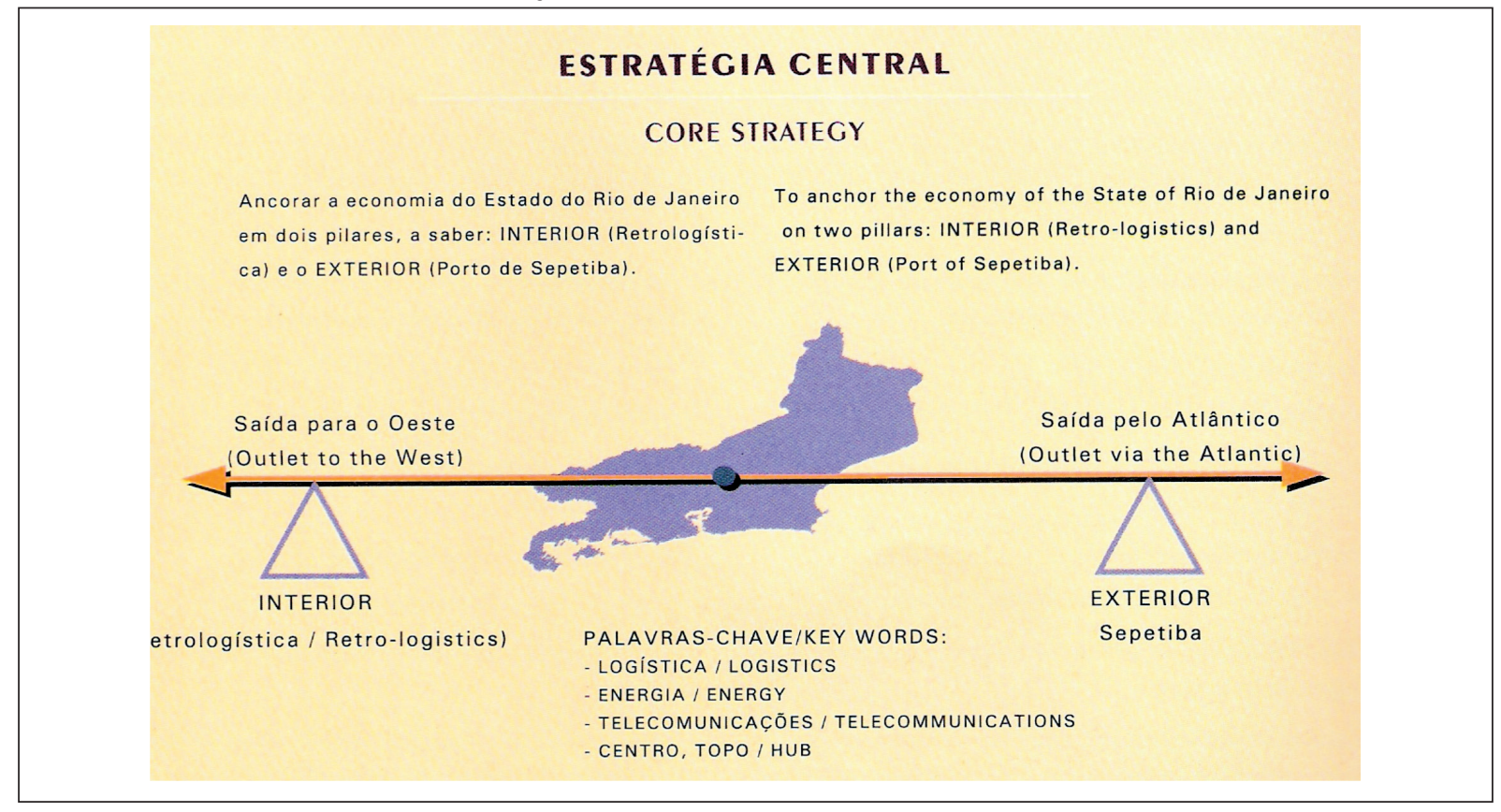

Fonte: FIRJAN, 1997

6 Deve-se destacar ainda a participação da FIRJAN na elaboração do Plano Nacional de Logística de Transportes, de 2006, o qual reservava expressivo volume de investimentos destinados à modernização do porto de Itaguaí e à construção do Arco Rodoviário entre outras medidas destinadas a consolidar a posição estratégica do Rio de Janeiro.

7 Local destinado à concentração e redistribuição dos fluxos. 
A transformação do Rio de Janeiro em um hub econômico, o papel do interior como um espaço de retrologística e a prioridade à atração de investimentos em logística portuária permanecem como as metas principais de outros estudos desenvolvidos pela FIRJAN a exemplo do "Mapa do Desenvolvimento do Estado do Rio de Janeiro", de 2006, que reúne metas e ações estratégicas para o período 2006-2015.

Outro estudo, “Decisão Rio: investimentos 2013-2014”, reúne informações sobre os investimentos anunciados e as oportunidades de negócios no Rio de Janeiro, devendo servir como instrumento de atração de novos investidores ao estado. Nesse trabalho foram mapeados 234 empreendimentos, com destaque para os investimentos em transporte e logística - como o Complexo Portuário do Açu (São João da Barra), o Arco Metropolitano e sua ligação com o Porto de Itaguaí e o COMPERJ (Itaboraí) -, e para os investimentos no interior do estado (setor automotivo, em particular no eixo sul fluminense, setor de construção naval e de exploração de petróleo e gás). De acordo com o relatório, esses empreendimentos reforçam a importância logística do Rio de Janeiro nacional e internacionalmente.

Por todos os impactos que os diversos investimentos na melhoria e na ampliação da infraestrutura logística do Rio de Janeiro vão provocar, percebe-se que o estado fortalecerá sua localização privilegiada. Capital nacional do petróleo, centro turístico internacional, sede de megaeventos esportivos e maior concentrador de investimentos do mundo, o estado ganhará mais um predicado: o de novo centro logístico do país, atuando como um estratégico hub internacional. Desse modo, o Rio de Janeiro continuará a oferecer excelentes oportunidades em diversos setores nos próximos anos, conforme apresentado a seguir. (FIRJAN, 2012:11)

Os projetos desenvolvidos pela FIRJAN reforçam a ideia de que, com o estímulo à implantação de novos empreendimentos e à expansão/modernização daqueles já existentes, os portos e sua rede logística poderiam efetivamente se constituir em um importante vetor para o desenvolvimento econômico do Estado do Rio de Janeiro. Dada a sua posição como nó central para o desenvolvimento de um sistema logístico no estado, os estímulos gerados pela modernização dos portos deveriam ser capazes de estimular a atração de investimentos no estado com estímulos diretos à modernização do transporte ferroviário, à formação de eixos rodoviários, à implantação de centros de serviços logísticos e ao desenvolvimento industrial.

Graças aos portos de alta capacidade em construção e à ampliação dos já existentes, a distância econômica para o resto do mundo também será reduzida, consolidando o Rio de Janeiro como importante centro logístico nacional e também internacional. De fato, até 2014, o estado terá o maior conjunto portuário do Atlântico Sul e um dos maiores do mundo, com 13 portos e três grandes terminais, o que representará uma grande instalação portuária a cada 39,7 km de costa. Nesses portos, serão transportados, além de contêineres, petróleo e derivados, minério de ferro, produtos siderúrgicos e automóveis, entre outros produtos. Com grande capacidade de armazenamento e escoamento de produtos e de atracação simultânea de vários navios com calados profundos, os portos do estado serão ainda mais estratégicos para a exportação e a importação de mercadorias. (FIRJAN, 2012:10)

Considerado o papel atribuído aos portos, nesses estudos, como polos irradiadores da estratégia de consolidação do Estado do Rio de Janeiro como um estado de logística, analisaremos na próxima parte as condições e as características do sistema portuário no Estado do Rio de Janeiro reorganizado, nas últimas décadas, a partir dos efeitos indutores de políticas públicas fortemente influenciadas por diretrizes identificadas nos projetos propostos pela FIRJAN.

\section{2 - O sistema portuário no Estado do Rio de Janeiro}

As primeiras e mais profundas transformações no sistema portuário brasileiro, de modo geral, resultaram de pressões dos principais agentes envolvidos direta e indiretamente no setor, 
o qual era regulado por decretos da década de 1930 e de 1970 e operava com equipamentos da década de 1940. A Lei No. 8630/1993, conhecida como Lei de Modernização dos Portos, foi um marco para o setor portuário brasileiro, pois estabeleceu um novo regime jurídico para exploração dos portos organizados e instalações portuárias, concentrando-se sobre a modernização técnica e a privatização da operação nos terminais portuários. ${ }^{8} \mathrm{O}$ modelo adotado pelo governo brasileiro para a exploração do sistema portuário era o LandlordPort ${ }^{9}$ ficando o Estado responsável pela infraestrutura e o setor privado, pela realização da operação portuária estabelecida por meio de arrendamentos (concessão).

A partir dos novos marcos legais o sistema portuário brasileiro alterou-se profundamente. Além de mudanças administrativas e da modernização técnica, houve expansão do número de Terminais de Uso Privativo, TUP - entre 1993 e 2013, o Brasil passou de 62 para 128 TUP instalados fora da Área do Porto Organizado, ${ }^{10}$ além de 34 portos públicos ${ }^{11}$ (ANTAQ, 2013).

A movimentação de cargas também foi ampliada, concentrando-se nos Terminais de Uso Privativo - em 2013, segundo dados da ANTAQ, 63\% das cargas (545 milhões de toneladas) movimentadas no Brasil passavam pelos TUP -, indicando a crescente importância dos Terminais de Uso Privativo na reestruturação do sistema portuário brasileiro. Na mesma época, os portos públicos movimentavam aproximadamente 289 milhões de toneladas de mercadorias.

O volume de investimentos públicos realizados entre 1993 e 2013 nos portos brasileiros é indicativo das transformações implementadas na esteira dos novos marcos regulatórios para o setor (Figura 2). Houve importante crescimento no volume de investimentos, associados aos Planos de Aceleração do Crescimento, PAC 1 e 2, concentrando-se em alguns períodos, 1993-1998, 2003-2007 e 2009-2012 (Pierdomenico, 2010).

Figura 2

Série Histórica dos Investimentos Públicos no Setor Portuário - 1995-2013*

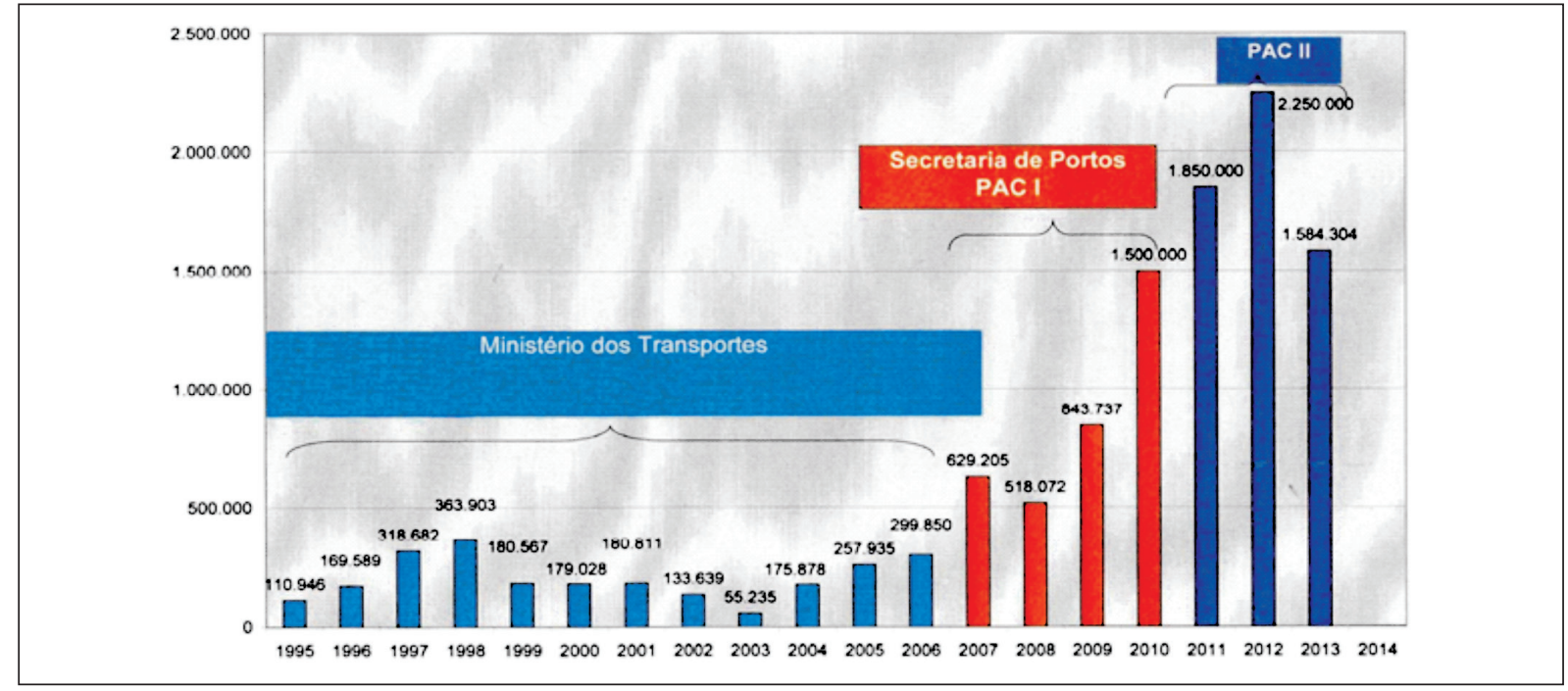

*1995-2009 (RAP + empreendimentos liquidados) 2010-2013 (LOA do Exercício e RAP)

Fonte: http://www.senado.leg.br/comissoes/ci/ap/AP20100629_Fabrizio_Pierdomenico.pdf.

Acesso em 25 de Abr. 2014.

80 Decreto $n^{0} .6620 / 2008$ estabeleceu três possibilidades de investimento no setor portuário: concessão/outorga de portos organizados por meio de licitação; arrendamento de instalações portuárias mediante licitação; outorga de autorização para construção e exploração de instalação de uso privativo (TUP). Recentemente a Lei $n^{0} .12 .815 / 2013$ e o Decreto $n^{0} .8033 / 2013$ definiram novos termos para exploração de Terminais de Uso Privado (TUP), Estação de Transbordo de Carga (ETC), Instalação Portuária de Turismo (IPT) e Instalação Portuária de Pequeno Porte (IP4). Em 2013, estavam previstas as licitações de 159 novos terminais, incluindo a construção de novos terminais e 0 arrendamento de terminais em portos públicos.

90 modelo LandlordPort foi adotado em vários dos principais portos do mundo: Barcelona e Valencia (Espanha); Hamburgo (Alemanha); Antuérpia (Bélgica); Roterdan (Holanda); Le Havre e Marcélia (França); Los Angeles e Houston (EUA).

10 Os Terminais de Uso Privativo podem ser instalados na Área do Porto Organizado, porto público, ou fora dela. Os TUP instalados na Área do Porto Organizado têm sua operação privativa autorizada mediante regime de arrendamento. Os TUP localizados fora do porto organizado funcionam sob regime de outorga de concessão e podem movimentar carga própria e de terceiros.

11 Dentre os portos públicos marítimos, 18 estavam em nome da União, administrados pelas Companhias Docas, 15 portos eram delegados a estados e municípios e um porto público concedido à iniciativa privada, Porto de Imbituba. 
Chama a atenção o volume de investimentos privados destinados/previstos para o setor (2010-2014) - R\$ 3.586 milhões em investimentos públicos e R 3.858 milhões em investimentos privados (PAC 2) -, reforçando a opção do governo brasileiro pela privatização da operação portuária, com destaque para as concessões para operação de terminais privativos em portos públicos, para a construção de novos terminais portuários e instalação de unidades de apoio à atividade portuária que respondem pela densificação da malha logística no país e no Estado do Rio de Janeiro (Figura 3).

Figura 3

Mapa Multimodal - Brasil

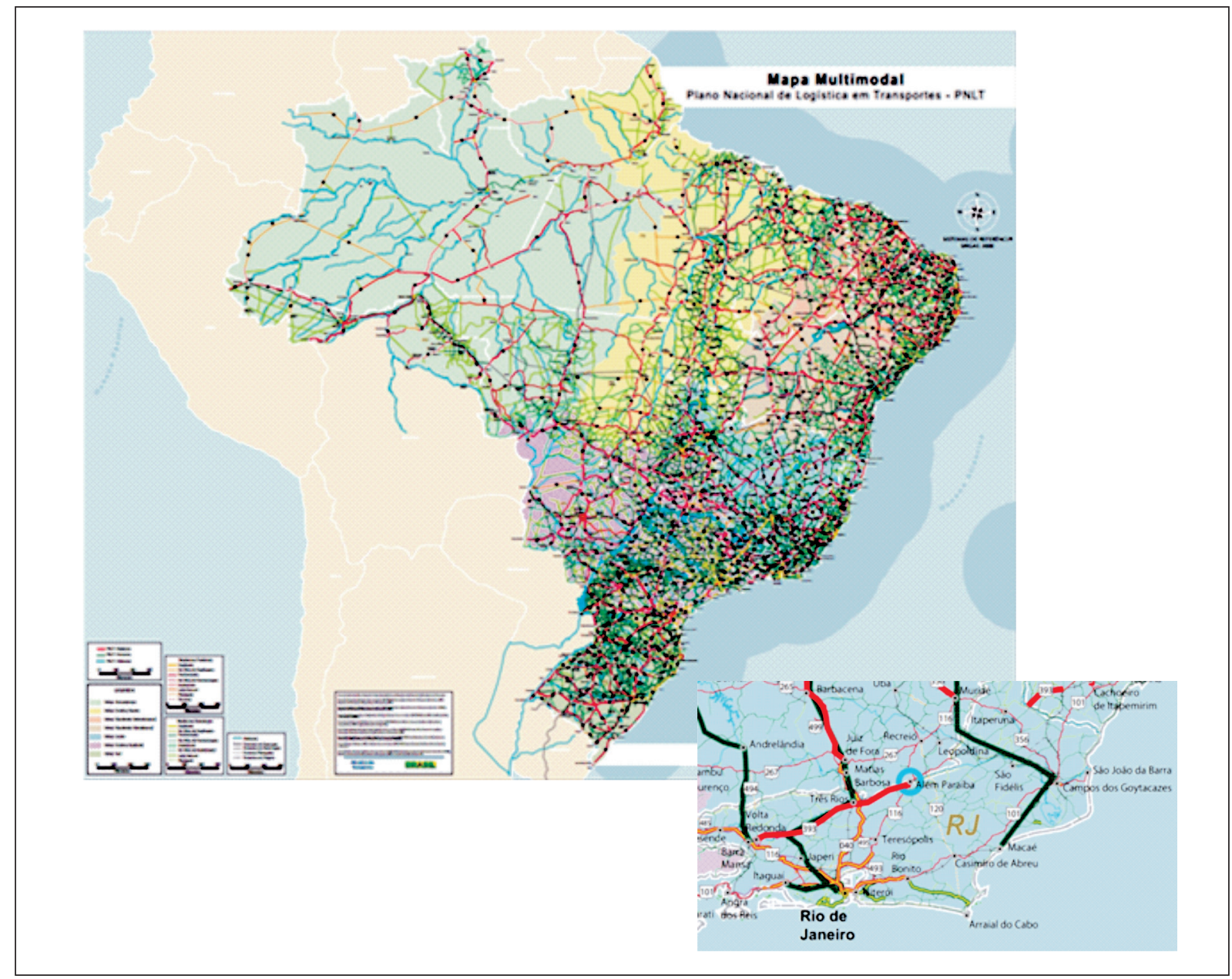

Fonte: Adaptado de Plano Nacional de Logística em Transportes - PNLT

O cenário no Estado do Rio de Janeiro não era diferente do conjunto do país e foi, do mesmo modo, profundamente transformado pela nova legislação. Funcionam atualmente no estado cinco portos públicos (Rio de Janeiro, Niterói, Forno, Angra dos Reis e Itaguaí), quatro deles administrados pela Companhia Docas do Rio de Janeiro, CDRJ, e 22 Terminais de Uso Privativo que colocam o estado na primeira posição em termos de expansão do sistema portuário - até 2012 um total de 128 TUP estavam instalados no país (Figura 4). Além dos terminais portuários, chama a atenção o grande número de estaleiros no estado (Figura 5), setor que viveu um período de profunda decadência e que, a reboque dos investimentos no setor petroquímico no estado, tem ampliado significativamente sua participação no PIB estadual. 
Figura 4

Terminais Portuários de Uso Privativo (TUP), outorgados

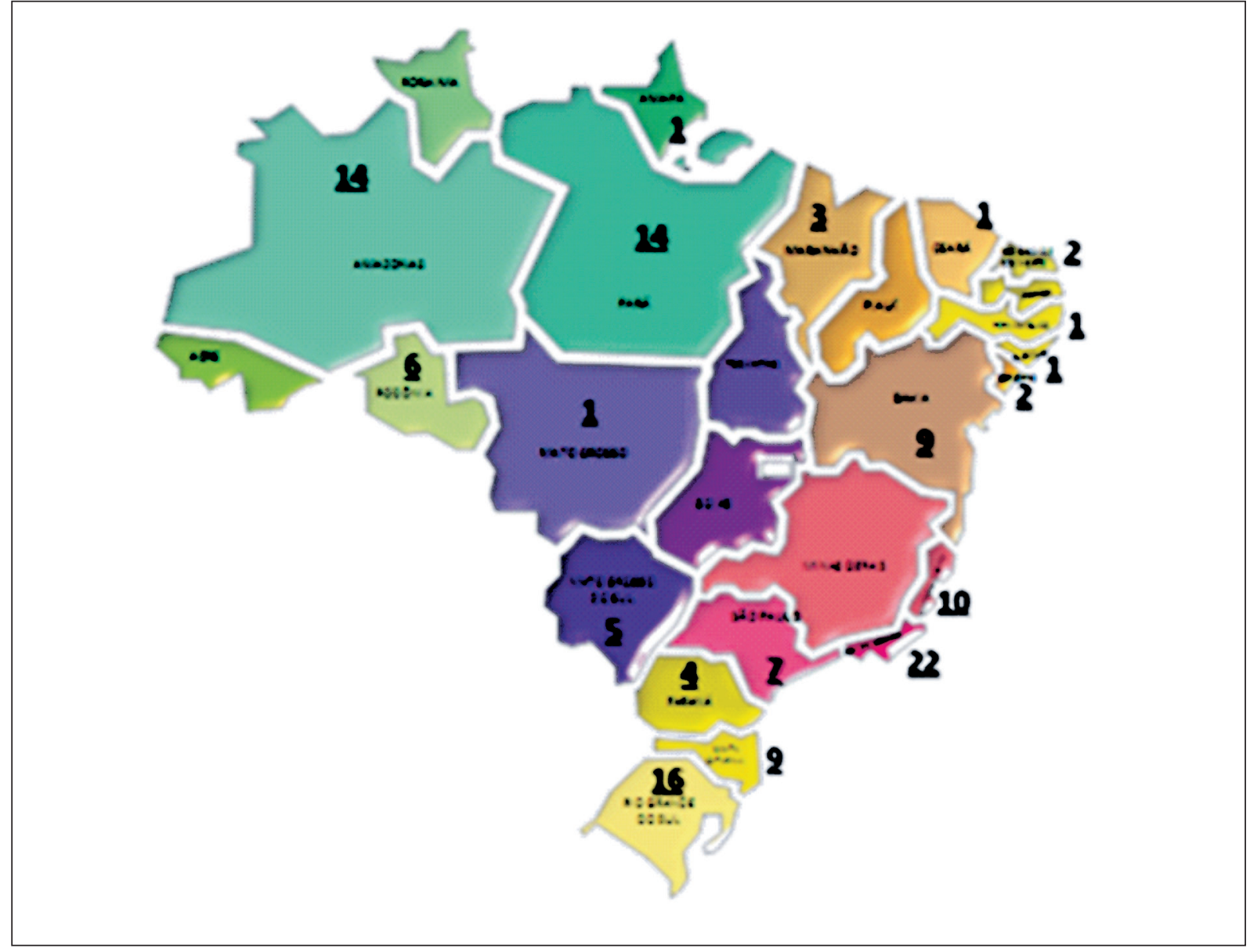

Fonte: Fonseca (2013)

Figura 5

Mapa dos Estaleiros no Brasi

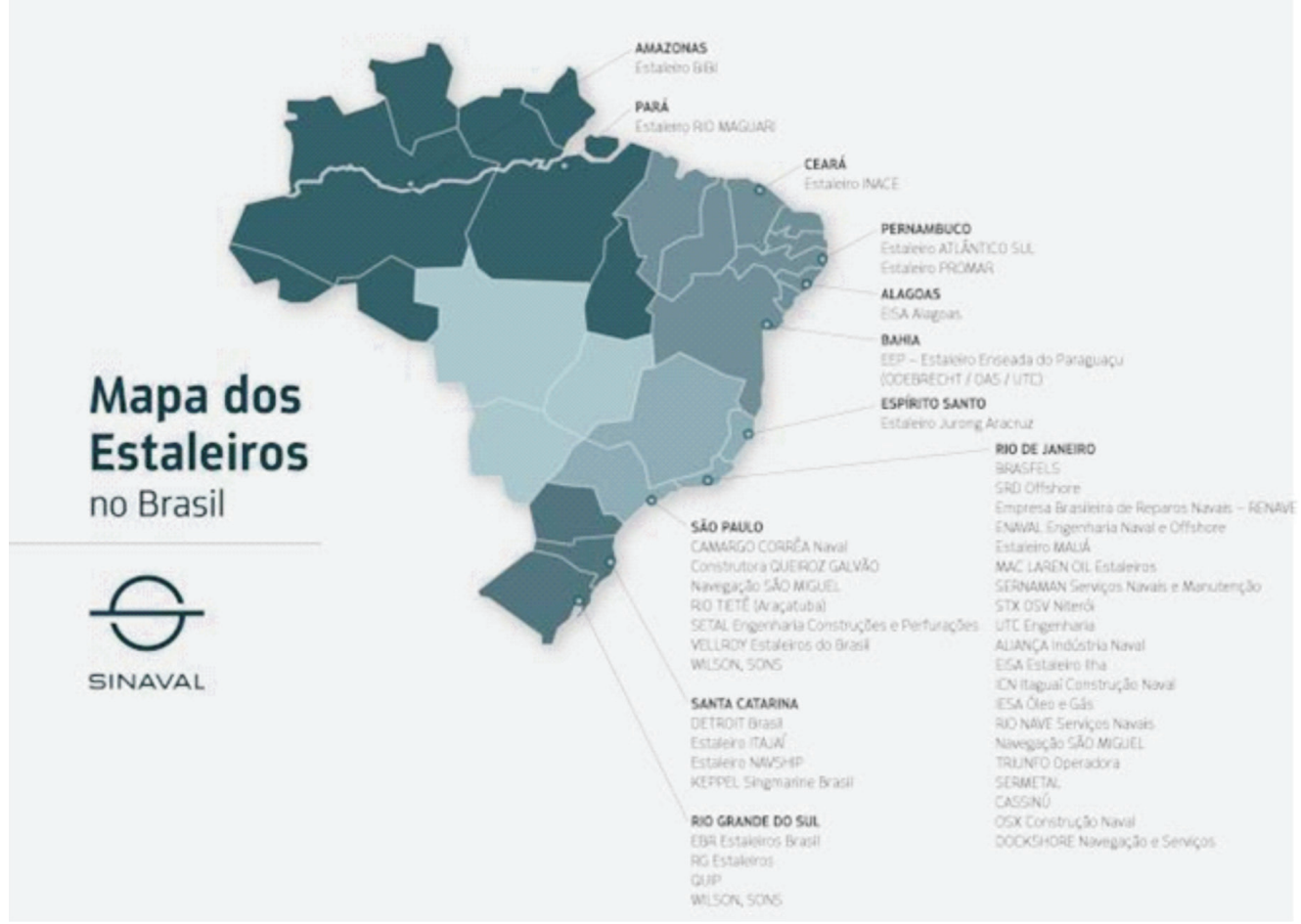

Fonte: Sindicato Nacional da Indústria da Construção e Reparação Naval e Offshore, disponível em: http://www.sinaval.org.br/docs/Mapa_EstaleirosBrasil.pdf. Acesso em 27 de abril de 2014. 
Desde a implementação da Lei de 1993, o sistema portuário do Estado do Rio de Janeiro registrou algumas importantes mudanças. O Porto do Forno teve sua administração municipalizada em 1999, passando a ser administrado pela Companhia Municipal de Administração Portuária, COMAP, criada pelo Município de Arraial do Cabo. Os portos de uso privativo preexistentes foram ampliados e modernizados, novos portos foram construídos, com destaque para as concessões obtidas pelos grandes complexos portuários, e um número importante de empresas arrendou terminais em portos públicos.

Destaca-se, no estado, a construção do Complexo Portuário do Açu (São João da Barra) e do Porto do Sudeste (Itaguaí), o projeto para implantação de um porto compartilhado entre a Petrobras, a Companhia Siderúrgica Nacional (CSN) e a Gerdau (Itaguaí) e de um porto destinado a escoar a produção do COMPERJ (Maricá), a ampliação da capacidade do Porto de Itaguaí e a expansão de atividades de apoio offshore à exploração e produção de petróleo nos portos de Angra dos Reis, Niterói e Forno. Outros TUP encontram-se em processo de autorização pelo governo federal para início das operações - Estaleiro Brasa e Subsea 7 do Brasil Serviços Ltda, em Niterói, Flexibras-TUP Technimp e Intermoor do Brasil Serviços Offshore de Instalação, em São João da Barra. Nos portos públicos, além do cais público propriamente dito, registrava-se, em 2013, a presença dos seguintes terminais: Moinho C. Sul S/A, Multi-Rio, Libra Terminal Rio, Multi-Car Terminal Veículos, Pier Mauá e Triunfo (São Cristóvão), no Porto do Rio de Janeiro; CSN, Valesul, SepetibaTecon S/A e CPBS, no Porto de Itaguaí; Terminal 1 (NITPORT) e Terminal 2 (NITSHORE) no Porto de Niterói; Angraporto, no Porto de Angra dos Reis.

Dados da ANTAQ apontam para a ampliação nos quantitativos de cargas movimentadas em alguns dos portos públicos e terminais de uso privativo no Estado do Rio de Janeiro, entre 2008 e 2012 (Quadro 2). Interessante observar que, no decênio anterior, 1998-2007, período subsequente à aprovação da Lei de Modernização dos Portos, os volumes de carga movimentada nos portos administrados pela CDRJ passaram de 9.785 para 48.021 milhões de toneladas. Além disso, houve importante ampliação do índice médio de conteinerização em especial nos terminais de uso privativo instalados nos portos públicos (Libra, Multi Rio e SepetibaTecon).

Quadro 2

Movimentação de cargas nos portos organizados e terminais uso privativo instalados no Estado do Rio de Janeiro 2008 e 2012 (em toneladas)

\begin{tabular}{|c|c|c|}
\hline PORTO & 2008 & 2012 \\
\hline Portos Organizados & & \\
\hline POR O DE ITAGUAÍ & 47.217 .575 & 57.081 .602 \\
\hline PORTO DO RIO DE JANEIRO & 8.773 .875 & 7.758 .349 \\
\hline PORTO DE ANGRA DOS REIS & 228.993 & 87.084 \\
\hline PORTO DE FORNO & 123.532 & 161.700 \\
\hline PORTO DE NITERÓI & 45.886 & 62.074 \\
\hline \multicolumn{3}{|l|}{ Terminais de Uso Privativo } \\
\hline TUP MBR & 37.670 .757 & 39.818 .902 \\
\hline TUP ALMIRANTE MAXIMIANO FONSECA & 30.195 .739 & 37.041 .162 \\
\hline TUP ALMIRANTE TAMANDARÉ (ILHA D’ÁGUA) & 10.648 .571 & 13.718 .404 \\
\hline TUP ILHA REDONDA & 313.989 & 172.935 \\
\hline TUP ILHA DO GOVERNADOR & 60.895 & 277.175 \\
\hline TUP ESTALEIRO MAUÁ & 6.252 & 10.799 \\
\hline TUP BRASFELS & - & 18.210 \\
\hline
\end{tabular}




\begin{tabular}{|c|c|c|}
\hline TUP DE GNL DA BAÍA DE GUANABARA & - & 2.264 .523 \\
\hline TUP ICOLUB & - & 58.313 \\
\hline TUP TERMINAL MARÍTIMO DE DUQUE DE CAXIAS & - & 105.468 \\
\hline TUP TERMINAL PORTUÁRIO TKCSA & - & 6.851 .970 \\
\hline TUP UTC ENGENHARIA & - & 9.319 \\
\hline TUP WELLSTREAM & - & 36.081 \\
\hline
\end{tabular}

Fonte: Organizado a partir do Anuário Estatístico Portuário e Sistema de Informações Gerenciais da ANTAQ (2013).

$\mathrm{Na}$ esteira das transformações na área portuária foram instaladas três Estações Aduaneiras Interiores - EADI, ${ }^{12}$ nos municípios de Resende, Nova Iguaçu e Rio de Janeiro, além de investimentos para ampliação da infraestrutura rodoviária, entre outras mudanças, as quais apontam para a instalação e expansão de uma rede logística que integra diferentes componentes territoriais no Estado do Rio de Janeiro (Figura 6).

Figura 6

Sistema Logístico-Portuário no Estado do Rio de Janeiro

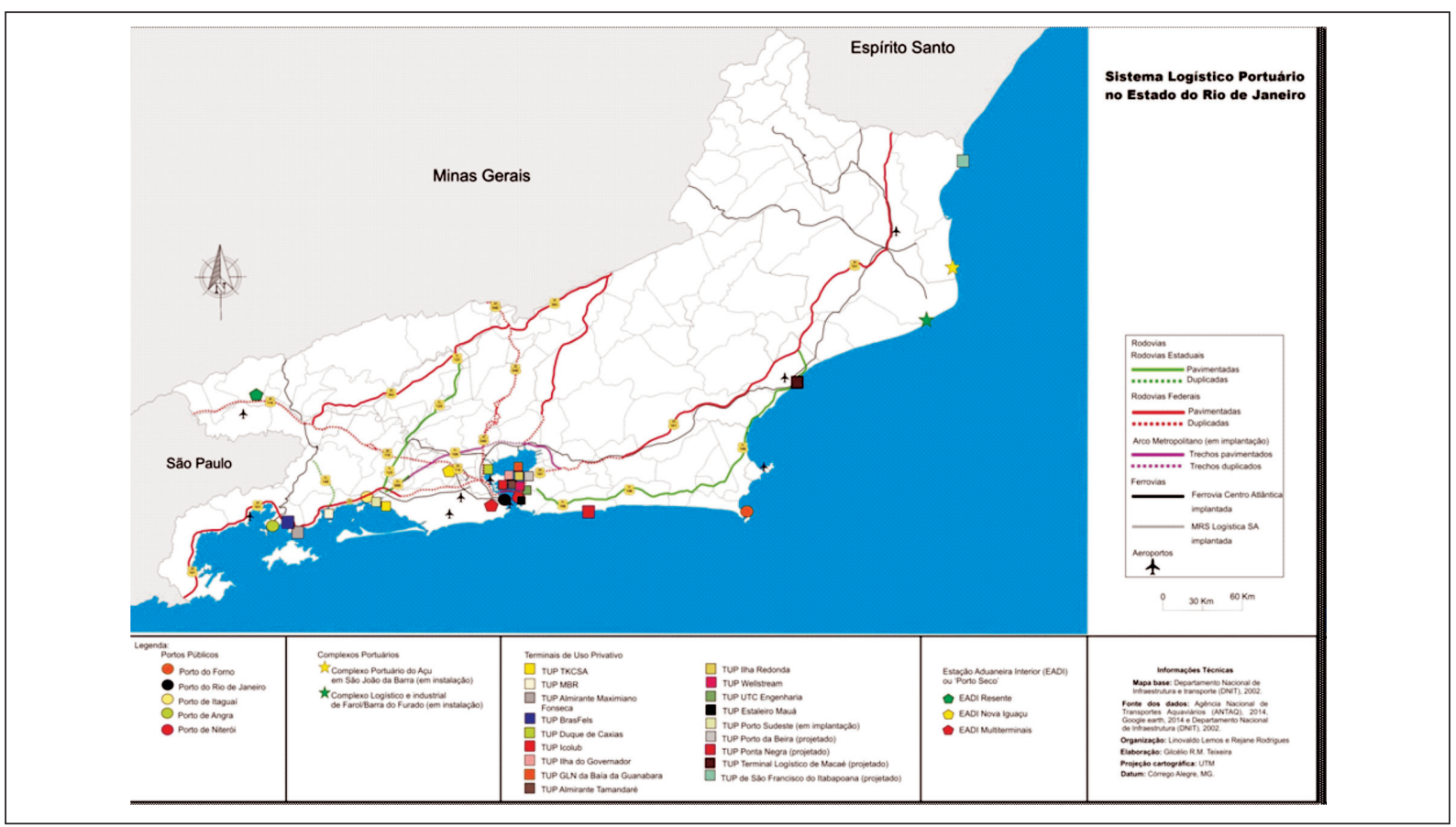

\section{Considerações finais}

O artigo revisitou a discussão a respeito das relações estabelecidas entre a metrópole e o chamado interior fluminense visando acrescentar ao debate o papel desempenhado pelo setor portuário e a rede logística a ele articulado vis-à-vis o crescimento e a dinamização das regióes do estado. Passando ao largo das visões que evocavam uma dicotomia capitalinterior, buscou-se acentuar as articulações e inter-relações capitaneadas principalmente pela importância crescente do setor portuário no contexto estadual.

Ênfase especial foi dada à atuação da Federação das Indústrias do Estado do Rio de Janeiro (FIRJAN), instituição privada com forte influência na definição de políticas públicas no estado. Ao discutir seus estudos, pôde-se demonstrar o papel estratégico atribuído ao 
setor portuário como vetor para projetos de desenvolvimento do Estado do Rio de Janeiro com ênfase no papel logístico dessa unidade da Federação no cenário regional e nacional.

Não foi objetivo deste artigo discutir o sentido e os interesses envolvidos na construção desta imagem e das políticas públicas de desenvolvimento para o estado, debate que pode ser encontrado em Rodrigues e Lemos (2013). Desejou-se chamar a atenção para algumas das mudanças que têm se processado, nas últimas décadas, e que, conduzidas por importantes atores institucionais, têm influenciado as ações do poder público com efeitos sobre a organização territorial do estado e a relação entre sua capital e o interior. A ampliação da infraestrutura portuária no estado e de suas articulações em uma rede logística são, como demonstrado, reveladoras dessas mudanças.

O pano de fundo da discussão foram as dinâmicas territoriais do estado que justificariam pensar numa reorganização do seu território, orientada por projetos privados e políticas públicas, com crescente participação e importância das demais regiões do estado (ou seja, para além da capital), procurando-se lançar luz justamente na rede logística que se configura a partir dos portos, rodovias e ferrovias no estado, conforme demonstrado na Figura 6. A linha de raciocínio aqui desenvolvida focou-se nessa rede logística como elemento aglutinador capaz de amalgamar as diversas regiões do estado, muito embora se mantenha a preeminência da sua capital.

\section{Referências bibliográficas}

ALENTEJANO, Paulo Roberto R. A evolução do espaço agrário fluminense. GEOgraphia, Ano 7, n. 13, 2005.

ANTAQ - Agência Nacional de Transporte Aquaviário. Relatório de Gestão 2012. MINT. 2013. BATISTA, Elieser. Infraestrutura de longo alcance para o desenvolvimento sustentado: Rio século XXI - uma contribuição do Sistema FIRJAN para o desenvolvimento do Rio de Janeiro. Rio de Janeiro: FIRJAN, 1997.

BATISTA, Ivone Lopes. Redes produtivas e novas terriorialidades no sul fluminense. Tese de doutorado. Rio de Janeiro: PPGG/UFRJ, 2006.

BELOCH, Israel; FAGUNDES, Laura Reis (Coord.). Sistema FIRJAN - a história dos 170 anos da representação industrial no Rio de Janeiro. Rio de Janeiro: Memória Brasil Projetos Culturais, 1997.

BINSZTOK, Jacob. Crise e construção de uma nova ordem territorial no Estado do Rio de Janeiro. GEOgraphia, Ano 1, n. 2, 1999.

CDRJ. Companhia Docas do Rio de Janeiro. Relatório Gestão 2007. Disponível em: http:// www.portosrio.gov.br/downloads/files/auditorias/relatorio_gestao_2007.pdf Acesso em: 03 mar. 2014.

CRUZ, José Luis Viana da. Os desafios da construção do desenvolvimento no Rio de Janeiro. Cadernos do Desenvolvimento Fluminense, Rio de Janeiro, n. 2, jul. 2013.

DAVIDOVICH, Fany. Metrópole e território: metropolização do espaço no Rio de Janeiro. Cadernos Metrópole n. 6, pp. 67-77, 2º sem. 2001. 
FAURÉ, Yves A., HASENCLEVER, Lia. NETO, Romeu e S. (Orgs.). Novos rumos para a economia fluminense: oportunidades e desafios de crescimento do interior. Rio de Janeiro, E-papers, 2008.

FAURÉ, Yves A., HASENCLEVER, Lia. (Orgs.). O desenvolvimento local no Estado do Rio de Janeiro: quarto estudos exploratórios no interior fluminense. Rio de Janeiro, E-papers, 2003.

. O desenvolvimento local no Estado do Rio de Janeiro: estudos avançados nas realidades municipais. Rio de Janeiro, E-papers, 2005.

FEDERAÇÃO DAS INDÚSTRIAS DO ESTADO DO RIO DE JANEIRO - FIRJAN. Infraestrutura de Longo Alcance para o desenvolvimento sustentado - Rio Século XXI. Rio de Janeiro: Sistema FIRJAN, 1997.

- Estudo de Impacto Ambiental do Projeto de Implantação do Arco Metropolitano do Rio de Janeiro BR 493/RJ109. Junho de 2007. Disponível em: http://www.firjan.org.br/site/anexos/ Decisaorio/2012-2014/RIMA_-_Arco_Metropolitano.pdf. Acesso em: 16 fev. 2014.

. Mapa do Desenvolvimento do Estado do Rio de Janeiro (2006-2015). Disponível em: http://www.firjan.org.br/data/pages/2C908CE921D5239A0121D554663232BC.htm. Acesso em: 16 fev. 2014.

. Decisão Investimentos Rio 2012-2014. Rio de Janeiro: Sistema FIRJAN, 2012. Disponível em: http://www.firjan.org.br/decisaoport2012-2014/files/decisaorio2012-2014_pt.pdf. Acesso em: 16 fev. 2014.

FONSECA, Fernando. Lei 12.815/2013 - Impactos no Setor Portuário da Bahia. In: 9º ENCONTRO ANUAL DA ASSOCIAÇÃO DE USUÁRIOS DOS PORTOS DA BAHIA (USUPORT), 2013.

GALVÃO, Maria do Carmo Corrêa. Rio de Janeiro: contradições e ajustes de um espaço desigual. Percursos geográficos. Rio de Janeiro: Lamparina, PPGG/UFRJ, 2009.

LESSA, Carlos. Rio de todos os Brasis: uma reflexão em busca de autoestima. Rio de Janeiro: Record, 2000.

LIMONAD, Ester. Rio de Janeiro, uma nova relação capital-interior? In: LIMONAD, Ester. HAESBAERT, Rogério. MOREIRA, Rui (Orgs.). Brasil século XXI por uma nova regionalização? Agentes, processos e escalas. Niterói: Max Limonad, 2004.

MEDEIROS JUNIOR, Helcio de. Desconcentração econômica e atratividade regional no Estado do Rio de Janeiro entre 2000 e 2010. Cadernos do Desenvolvimento Fluminense, Rio de Janeiro, n.1, fev. 2013.

MINT. Ministério dos Transportes. Relatório Executivo do Plano Nacional de Logística e Transportes. 2006.

OSÓRIO, Mauro. Rio nacional, Rio local: mitos e visões da crise carioca e fluminense. Rio de Janeiro: Senac, 2005.

PIERDOMENICO, Fabrizio. Audiência Pública. Senado Federal. Comissão de Agricultura e Reforma Agrária. Comissão de Infraestrutura. 2010. Disponível em: http://www.senado.leg. br/comissoes/ci/ap/AP20100629_Fabrizio_Pierdomenico.pdf Acesso em: 02 mar. 2014.

PINHEIRO, Armando Castelar; VELOSO, Fernando (Orgs.). Rio de Janeiro: um estado em 
transição. Rio de Janeiro: Editora da FGV, 2012.

RIBEIRO, Luís César de Queiroz. As necessidades do planejamento urbano para o Estado do Rio de Janeiro. Revista de Economia Fluminense, Ano VII, n. 14, out. 2013.

RIO DE JANEIRO, Secretaria de Transportes. Mapeamento do Sistema Logístico de Cargasdo Estado do Rio de Janeiro e de Sistemas Logísticos Concorrentes / Complementares, com Modelagem e Definição de Demanda. Relatório Final do Mapeamento - Etapa 1 do Plano Estadual de Logística de Cargas do RJ -Vol. 1/2; vol.2/2.2011.

RODRIGUES, Rejane C. A. e LEMOS, Linovaldo Miranda. Logística Portuária e Dinâmicas Territoriais nos Municípios Brasileiros. In: XIV ENCONTRO DE GEÓGRAFOS DA AMÉRICA LATINA, EGAL. Anais... Lima, Peru, 2013.

SILVA, Augusto César Pinheiro da. A produção acadêmica sobre a gestão do território no Estado do Rio de Janeiro: o projeto FAPERJ 2008-2011 no geTERJ da PUC-Rio. GEOPUC Revista do Departamento de Geografia da PUC-Rio. Ano 4, n. 7, $2^{\circ}$ sem. 2011.

URANI, André. Trilhas para o Rio: do reconhecimento da queda à reinvenção do futuro. Rio de Janeiro: Elsevier/Campos, 2008.

. GIAMBIAGI, Fabio. Rio: a hora da virada. Rio de Janeiro: Elsevier/Campos, 2011. 
